\title{
Is thickening of the basal lamina in the saphenous vein a hallmark of smoking?
}

\author{
D J Higman, J T Powell, R M Greenhalgh, A Coady, J Moss
}

\begin{abstract}
Objective-To investigate whether smoking causes ultrastructural changes in the intima of the proximal saphenous vein. Design-Proximal saphenous veins from heavy smokers and non-smokers were examined with scanning and transmission electron microscopy to determine changes in surface ultrastructure, in the intercellular junction, and in the thickness of the basal lamina. Immunogold labelling was used to identify specific components of the endothelial basal lamina.

Material-Vein specimens were obtained from patients undergoing varicose vein surgery (12 patients) or distal bypass surgery (eight patients).

Main results-The only ultrastructural change that discriminated between specimens was thickening of the endothelial basal lamina. All specimens with a thickened basal lamina were from heavy smokers. Immunogold labelling studies showed that the thickened basal lamina contained specific accumulations of fibronectin but not heparan sulphate proteoglycans, type IV collagen, or laminin.

Conclusions-Two ultrastructural characteristics are associated with smoking: thickening of the endothelial basal lamina and a specific accumulation of fibronectin in the thickened basal lamina. Such abnormalities in the saphenous veins from smokers may contribute to the poorer performance of these veins as bypass conduits.
\end{abstract}

(Br Heart f 1994;71:45-50)

Department of Surgery D J Higman J T Powell

R M Greenhalgh

Department of Histopathology, Charing Cross and

Westminster Medical

School, London

A Coady

J Moss

Correspondence to:

D J Higman, Department of Surgery, Charing Cross and Westminster Medical School, Fulham Palace Road, London W6 8RF.

Accepted for publication 9 August 1993
The saphenous vein is widely used for both distal and coronary artery bypass surgery. ${ }^{12}$ Several studies have shown that continued cigarette smoking is associated with a significant increase in the risk of occlusion of the bypass graft. ${ }^{3-5}$ The mechanisms of occlusion include intimal hyperplasia, graft thrombosis, and the development of focal stenoses. ${ }^{6}$ In the vasculature of the human umbilical cord noticeable ultrastructural changes have been associated with maternal smoking. ${ }^{7}$ These changes include "blebbing" of the endothelium, opening of endothelial intercellular junctions, subendothelial oedema, and widening of the basal lamina. Uterine arteries from smokers also showed discontinuity between endothelial cells on scanning electron microscopy. ${ }^{8}$

Here we have investigated, with electron microscopy and immunogold labelling of components of the basal lamina, whether there were ultrastructural changes in the saphenous veins of smokers, that might predispose these veins to occlusion when used as arterial bypass grafts.

\section{Patients and methods}

This study was approved by the local ethics committee and all patients gave informed consent. Segments of proximal long saphenous vein were obtained with minimal trauma from two groups of patients, those having ligation and excision of the long saphenous vein for the correction of varicose veins $(n=12)$ and those having arterial bypass surgery for critical ischaemia of the lower limb $(n=8)$. Even in patients with varicose veins the proximal saphenous vein was minimally dilated, with no disease evident on light microscopy. Smokers were defined as current smokers with at least a 10 pack-year history of smoking. In the varicose vein group, non-smokers were patients who had never smoked and in the vein bypass group, the non-smokers were those patients who had not smoked for at least five years. Serum samples were obtained at the time of surgery for the estimation of cotinine, the principal stable metabolite of nicotine: cotinine concentrations of $>200$ nmol/1 were considered indicative of current smoking. Patients with diabetes, on antihypertensive treatment, or those who had a history of venous thrombosis or venous surgery were excluded from this study. Duplex scan confirmed a competent long saphenous system in all patients undergoing bypass surgery.

After rinsing the vein specimens in phosphate buffered saline $(\mathrm{pH} 7 \cdot 2)$ at $37^{\circ} \mathrm{C}$, specimens were processed for electron microscopy and immunogold studies as described later. A segment of the specimen was also fixed in $10 \%$ buffered formalin for light microscopy.

\section{ELECTRON MICROSCOPY}

A $2-3 \mathrm{~cm}$ segment of saphenous vein was cannulated with a modified polythene connector and distended with 3\% glutaraldehyde in $0.1 \mathrm{M}$ cacodylate buffer $(\mathrm{pH} 7 \cdot 2)$ from a reservoir at a pressure of $40 \mathrm{~cm}$ of water; this was the minimum pressure required to restore the vein segment to the approximate diameter in vivo. The distended vessel was fixed overnight by immersion in $3 \%$ buffered 
glutaraldehyde. For scanning electron microscopy, the vessel was divided longitudinally, thoroughly washed with $0 \cdot 1 \mathrm{M}$ cacodylate buffer $(\mathrm{pH} 7 \cdot 2)$ for two hours, post fixed in $1 \%$ osmium tetroxide for one hour, dehydrated with graded ethanols (30-100\%) for three hours and critical point dried. Specimens were then mounted on aluminium stubs and coated with a layer of gold about $50 \mathrm{~nm}$ thick. For transmission electron microscopy, specimens were post fixed in $2 \%$ aqueous osmium tetroxide, dehydrated through ascending grades of ethanol, and embedded in Spurr's resin. Ultrathin sections were stained with aqueous uranyl acetate and Reynold's lead citrate.

\section{EXAMINATION OF LIGHT AND ELECTRON MICROSCOPY SPECIMENS}

All sections and micrographs were examined blind, - that is, with no prior knowledge of the patients concerned or their smoking habits.

\section{IMMUNOGOLD STUDIES}

The processing of samples was based on the technique of Woodrow et $a l^{9}$ Specimens were placed in $4 \%$ paraformaldehyde in $0.1 \mathrm{M}$

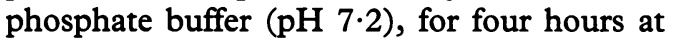
$4^{\circ} \mathrm{C}$, dissected into blocks $4 \mathrm{~mm} \times 1 \mathrm{~mm} \times$ $1 \mathrm{~mm}$, and stored in $1 \%$ paraformaldehyde for three days. The fixed samples were rinsed briefly in phosphate buffer at $4^{\circ} \mathrm{C}$. All further processing was carried out at about $-25^{\circ} \mathrm{C}$. The tissue was rapidly dehydrated through ascending grades of ethanol over 30 minutes, infiltrated with $1: 1$ then 1:2 ethanol: Lowicryl K4M mixtures (Taab Laboratories UK) for 30 minutes, and left for one hour and then overnight in fresh Lowicryl K4M. Embedding was carried out in brimming, sealed gelatin capsules of Lowicryl, with polymerisation under ultraviolet light for 20 hours at $-30^{\circ} \mathrm{C}$ in a UVF-35 cold cabinet (Agar Scientific, Stanstead, UK), then by two days at room temperature.

Gold coloured sections were collected on uncoated nickel grids. These were labelled with gold by immersion in drops of the following solutions at room temperature: $1 \%$ ovalbumin (grade V, Sigma, UK) in modified phosphate buffered saline (MPBS) for 25 minutes, primary antibody in MPBS for two hours, washes in five drops of MPBS over 15 minutes, goat anti-rabbit IgG conjugated to $10 \mathrm{~nm}$ gold (Biocell Research Laboratories, Cardiff, UK) in MPBS for 30 minutes,

Table Origin of saphenous vein samples and the presence of thickening of the basal lamina

\begin{tabular}{lllll}
\hline & Number (male) & $\begin{array}{l}\text { Median age } \\
\text { (range, yr) }\end{array}$ & $\begin{array}{l}\text { Cotinine } \\
\text { range } \\
\text { (nmol/l) }\end{array}$ & $\begin{array}{l}\text { Basal lamina } \\
\text { thickening }\end{array}$ \\
\hline $\begin{array}{l}\text { Non-smokers: } \\
\quad \text { Varicose vein correction }\end{array}$ & $6(3)$ & $50(40-65)$ & $35-161$ & $0 / 6$ \\
$\begin{array}{l}\text { Bypass surgery } \\
\text { Smokers: }\end{array}$ & $4(2)$ & $72(65-78)$ & $38-82$ & $0 / 4$ \\
$\quad \begin{array}{l}\text { Varicose vein correction } \\
\text { Bypass surgery }\end{array}$ & $6(1)$ & $40(34-60)$ & $207-1541$ & $6 / 6$ \\
\hline
\end{tabular}

The immunogold labelling studies were carried out on a subset of samples obtained at surgery The immunogold labelling studies were carried out on a from four non-smokers aged 40-61 (two men) and four smokers aged 39-54 (one man). washes in five drops of MPBS over 10 minutes, and a final wash in several drops of distilled water. The sections were stained for 30 minutes in $1 \%$ aqueous uranyl acetate and in Reynolds' lead citrate for five minutes.

The MPBS contained phosphate buffered saline ( $\mathrm{pH} \mathrm{7.2)}$ with $0.05 \%$ Tween $20,0 \cdot 1 \%$ bovine serum albumin (Sigma, UK) and 0.02 $M$ sodium azide. In control sections the primary antiserum was omitted or replaced with normal rabbit serum.

\section{IMMUNOLOGICAL REAGENTS}

Rabbit antihuman plasma fibronectin (A245) was obtained from DAKO, Buckinghamshire, $\mathrm{UK}$, rabit antibovine heparan sulphate proteoglycans was a gift from Professor RG Spiro, Harvard Medical School, Boston, USA, ${ }^{10}$ rabbit antihuman placental type IV collagen (10411) was obtained from Institut Pasteur de Lyon, France, and rabbit antihuman placental laminin (AB949) from Chemicon International, London.

\section{Results}

The table shows the demographic details of patients. All the patients considered as nonsmokers had cotinine concentrations $<200$ $\mathrm{nmol} / \mathrm{l}$ and all the smokers had cotinine concentrations in excess of this value. Light microscopy examination of vein segments did not show any gross intimal thickening or damage in any of the specimens.

\section{SCANNING ELECTRON MICROSCOPY}

Cytoplasmic blebs were not seen in any of the specimens examined. Microvilli were seen in specimens from both smokers and non-smokers, with no apparent difference between the two groups. Intercellular boundaries were conspicuous and cells were in close apposition (fig 1). In some regions, separation of endothelial cells had occurred, but this was not confined to specimens from smokers, and was associated with splits in the cytoplasm, suggesting that the spaces between cells were due to a preparation artifact.

\section{TRANSMISSION ELECTRON MICROSCOPY}

Widening of the interendothelial cell junctions and subendothelial oedema were not noted in any of the specimens examined. Intracellular organelles were generally well preserved and there was no dilatation of endoplasmic reticulum or vacuolation of the cytoplasm. A distinct difference was noted, however, between specimens with respect to the thickness of the endothelial basal lamina, and specimens could be divided into two groups; those having normal basal lamina and those showing areas of thickening. In the normal group, the basal lamina appeared as a narrow continuous layer immediately beneath the endothelial cells, and elastic fibres and bundles of microfibrils were seen beneath the basal lamina (fig 2). In the other group, the basal lamina was grossly thickened, up to about 50 times normal, and appeared as a wide amorphous or faintly fibrillar layer 
Figure 1 Scanning electron micrograph of saphenous vein from a non-smoker. Bulges (*) denote the position of the nuclei. Cell boundaries are conspicuous (arrow) and splits are seen in the adjacent cytoplasm (white arrow). Originally

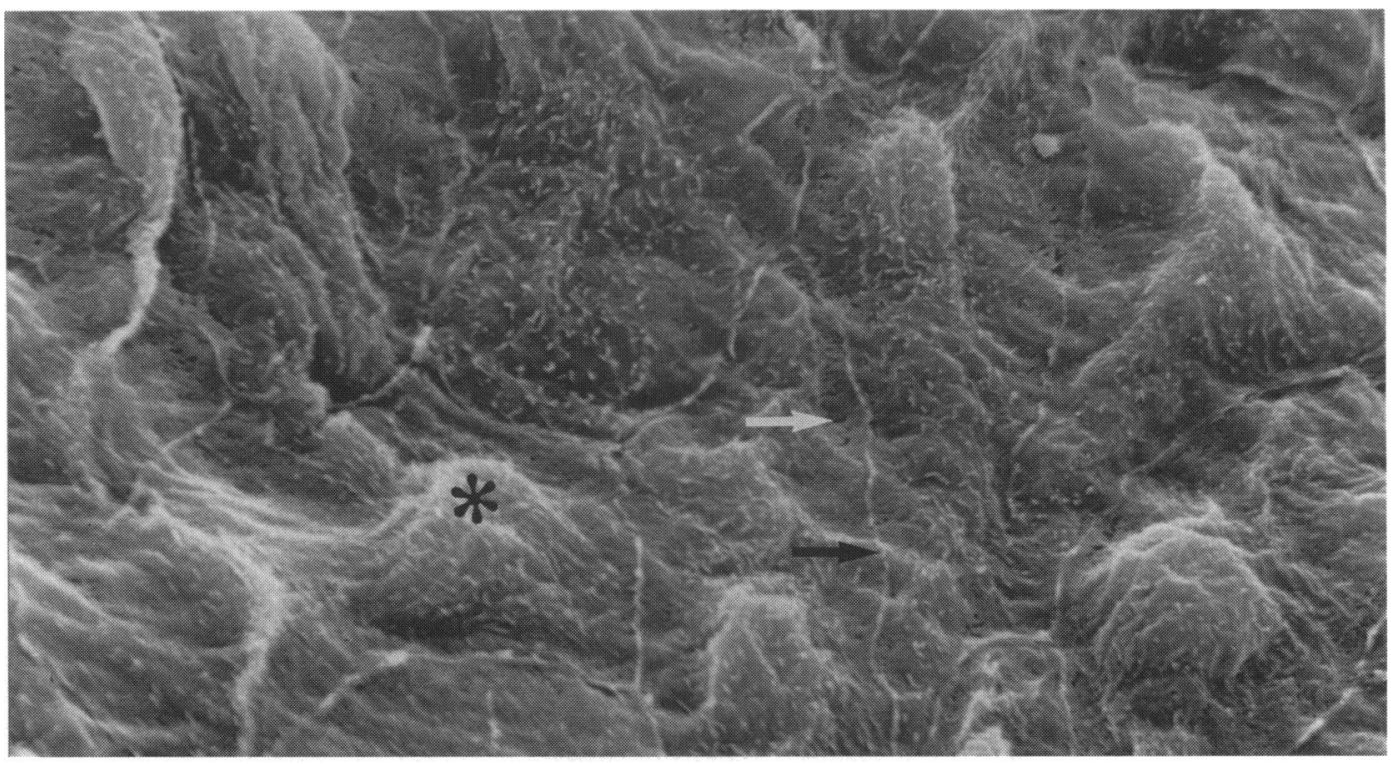

beneath the endothelial cells (fig 3). In some regions the thickening was continuous, running beneath several cells, whereas in others, the gross thickening seemed to be focal, with adjacent areas of basal lamina being of normal thickness (fig 3). The basal lamina was always distinct from the banded collagen and microfibrils. Areas of thickened basal lamina were seen in specimens from both the varicose group and the bypass group.

When the serum cotinine concentrations of the patients of these specimens were compared, it was found that specimens containing areas of thickened endothelial basal lamina were from patients with high cotinine concentrations (smokers, table). Although nonthickened normal basal lamina was seen in specimens from both smokers and non- smokers, areas of thickening were not seen in specimens from the non-smoking group.

\section{IMMUNOGOLD STUDIES}

In specimens from non-smokers, immunogold labelling for fibronectin was seen along regions of the basal lamina of endothelial cells and the external lamina of smooth muscle cells (fig 4); similar regions were also seen in specimens from smokers. Also in smokers, there were accumulations of numerous gold particles over the finely fibrillar material of the thickened regions of basal lamina (fig 5). Fibronectin however was not associated with subintimal bundles of microfibrils. The typical amorphous thickening of basal lamina seen on routine section was not identified on the Lowicryl sections, in which the thickened
Figure 2 Electron micrograph of saphenous vein intima from a nonsmoker showing thin endothelial basal lamina (arrow), microfibrils ( $m$ ) and intimal smooth muscle cell (s). Originally $\times 21000$

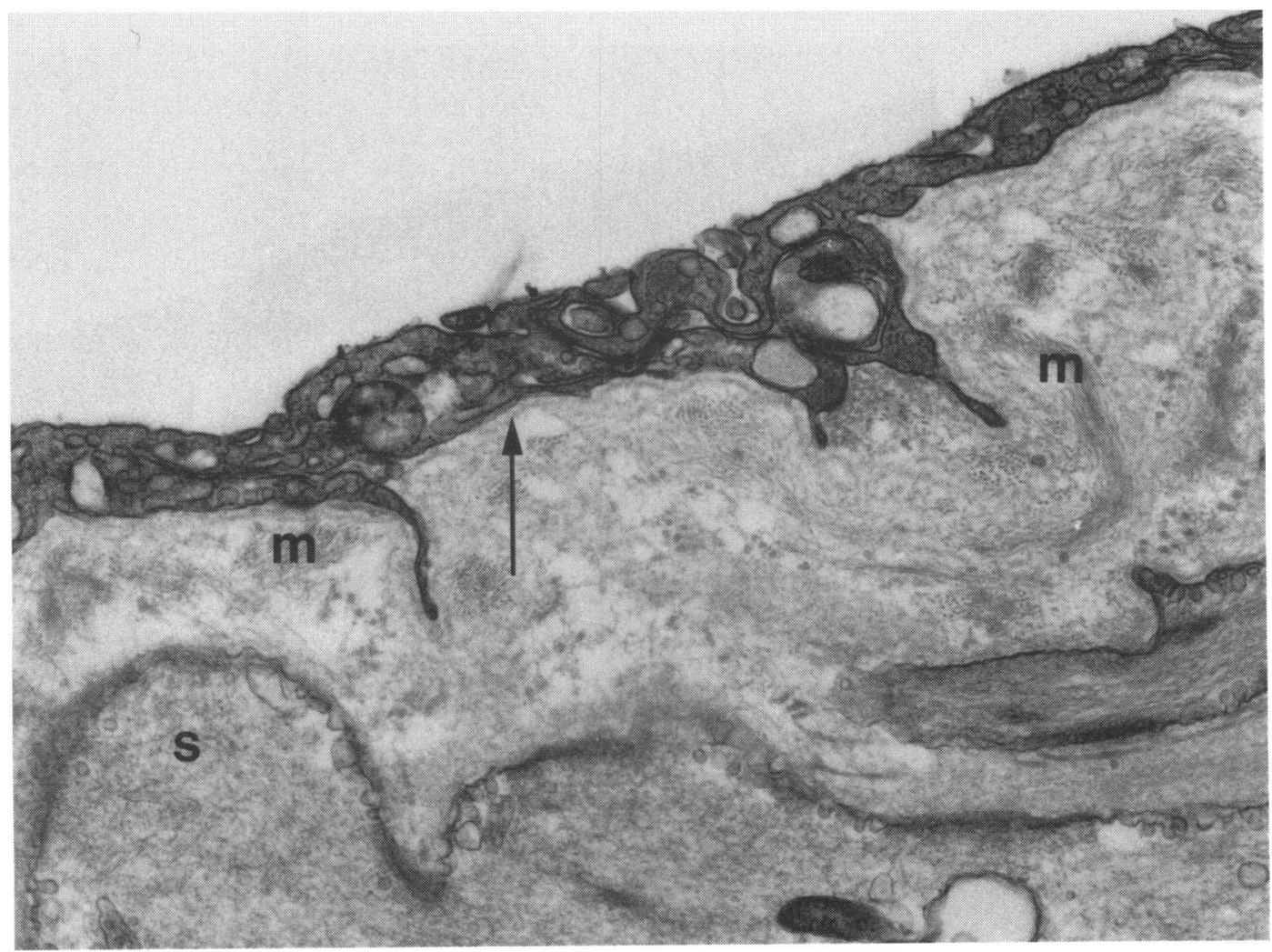


Figure 3 Electron micrograph of saphenous vein intima from a smoker showing focal thickening of the endothelial basal

lamina (bl), adjacent basal lamina of normal thickness (arrow), collagen fibres (c) and the external lamina (ex) of a smooth muscle cell (s). Originally $\times 21000$.

Figure 4 Electron micrographs of labelling for fibronectin in saphenous vein from a non-smoker to show immunogold particles localised mainly to the basal lamina of the endothelial cell (arrows) and external lamina of the smooth muscle cell (short arrows). Originally $\times 44000$.

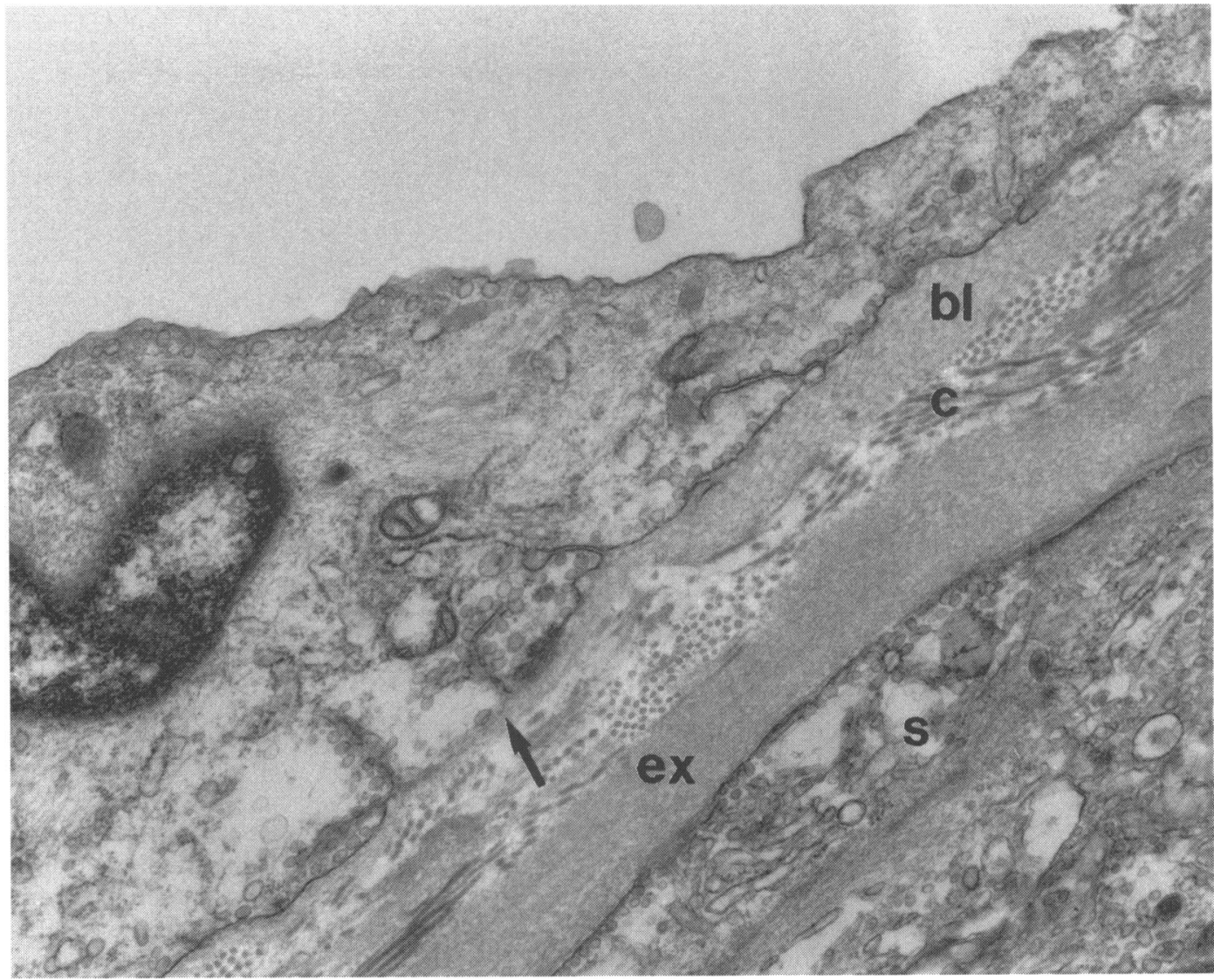

regions appeared as finely fibrillar material, similar morphologically to the subintimal bundles of microfibrils. Therefore it was difficult to correlate the morphology of tissue embedded in Spurr's resin for routine electron microscopy with the tissue embedded in Lowicryl for immunogold labelling, which had low contrast.

Heparan sulphate proteoglycans were

localised to the endothelial basal lamina and external lamina of the smooth muscle cells, a pattern similar to that seen in the fibronectin stained sections from the non-smoking group, but there was no increase in the thickened basal lamina seen in sections from smokers. Immunogold labelling for type IV collagen and laminin was diffuse throughout the subendothelium, and for type IV collagen was

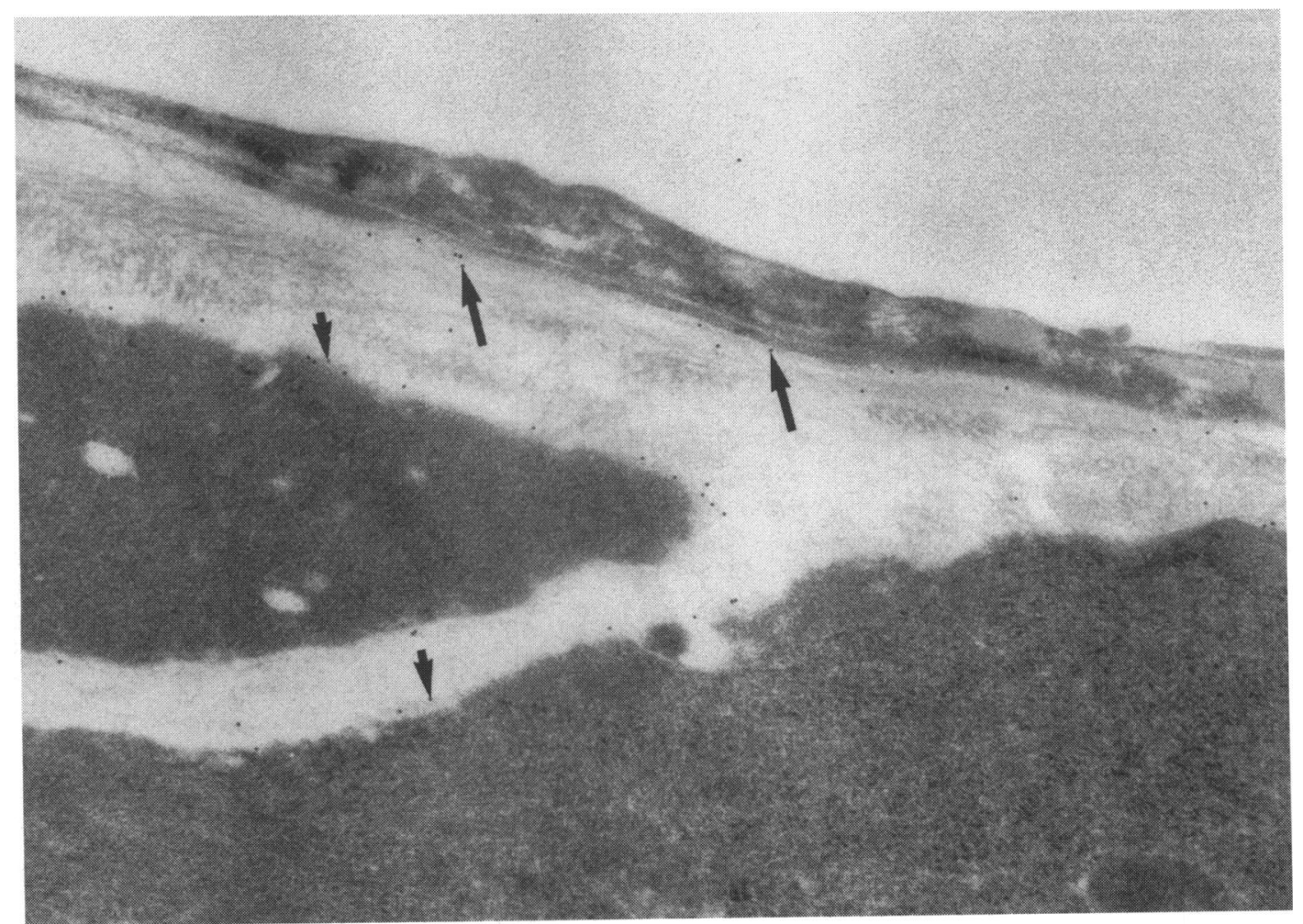


Figure 5 Electron micrograph of labelling for fibronectin in the saphenous vein from a smoker to show localisation of gold particles to accumulations of material in the region of the endothelial basal lamina: microfibrils. Originally $\times 42000$.

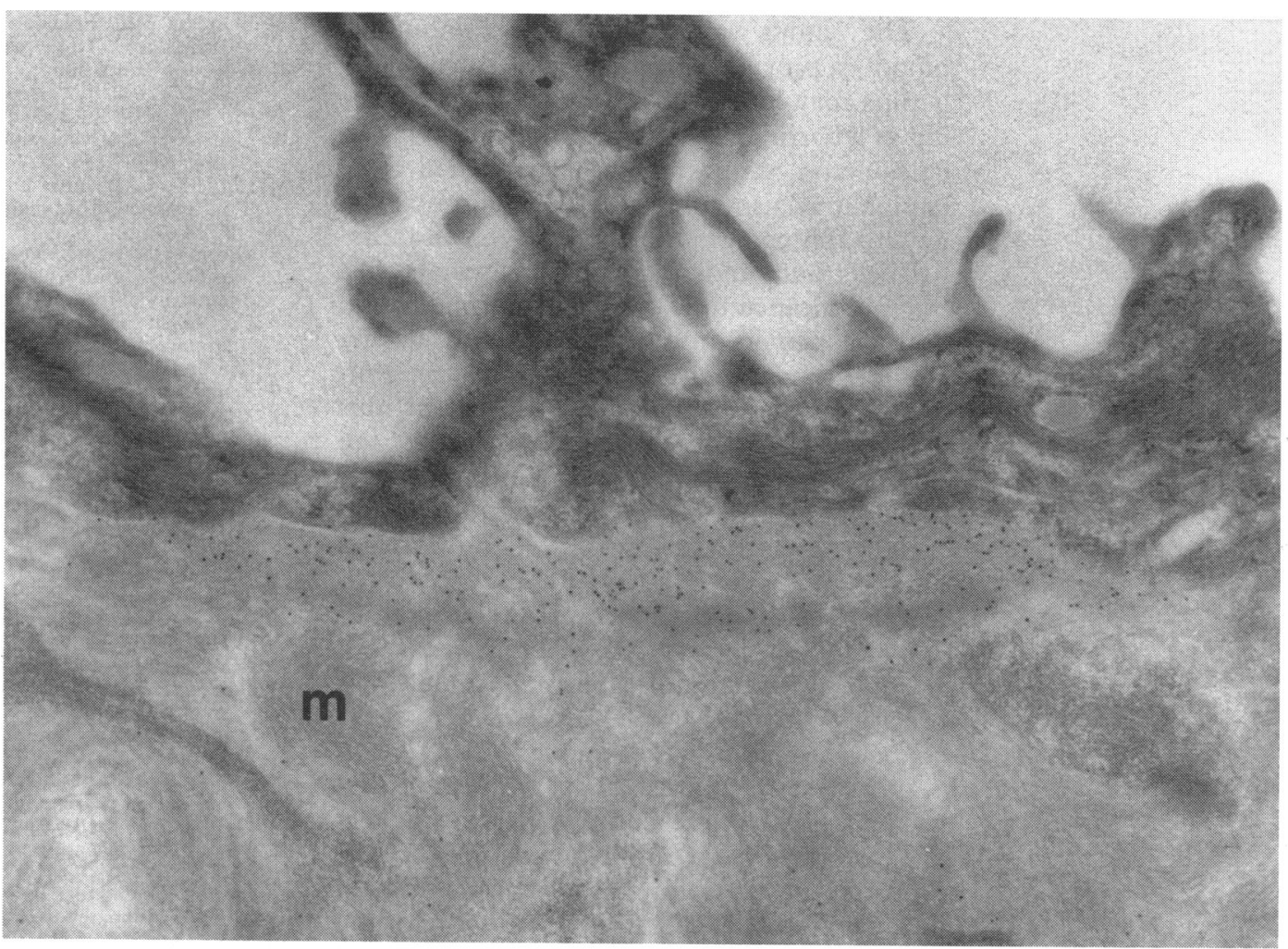

associated particularly with the subintimal bundles of microfibrils. No localisation of gold particles was seen associated with the finely fibrillar thickening of the basal lamina present in smokers, and there was no obvious difference in distribution between specimens from non-smokers and smokers.

\section{Discussion}

Smoking related ultrastructural changes have been reported in human umbilical and uterine arteries. ${ }^{78}$ On scanning electron microscopy, gaps between endothelial cells were associated with smoking in both vessels but this finding has not been confirmed in our study of the saphenous vein. Separation of the cells seemed to be artifactually produced by shrinkage of the specimen, which can occur during critical point drying. ${ }^{11}$ The blebs described in human umbilical arteries from smokers were not seen in the uterine artery, or in our study of the saphenous vein, and would not therefore be a consistent marker of smoking.

The most prominent feature associated with smoking on transmission electron microscopy in umbilical arteries was focal thickening of the basal lamina, and subendothelial oedema. Less noticeable differences were dilatation of the endothelial endoplasmic reticulum and widening of endothelial cell junctions. Thickened basal lamina has been reported in conditions other than smoking. It is well documented in diabetic microangiopathy,,$^{12} 13$ and has also been reported as an age and sex related change in muscle capillaries, being greatest in elderly men. ${ }^{14}$ In animal models of endothelial injury, thickened endothelial basal lamina has been found after exposure to radiation or cytotoxic drugs. ${ }^{15}$
In this study, focal thickening of the endothelial basal lamina enabled discrimination between saphenous vein specimens from smokers and non-smokers, when examined blind with no prior knowledge of the patient's smoking habits, irrespective of whether the vein was harvested at bypass surgery or surgery for varicose veins. This morphological finding is in agreement with the reported studies on human umbilical vessels. Diabetes and advanced age can be excluded as causes of this thickening as diabetic patients were not included in this study, and thickening of the basal lamina was not seen in the nonsmokers of the older bypass group. By contrast with the reports on umbilical vessels, subendothelial oedema, dilatation of endoplasmic reticulum, and widening of intercellular junctions were not seen in the saphenous vein of smokers.

The endothelial basal lamina is a complex mesh like structure and with immunohistochemical techniques the main protein components have been identified as fibronectin, type IV collagen, heparan sulphate proteoglycans, and laminin. ${ }^{16}{ }^{17}$ Immunogold labelling of saphenous vein specimens from smokers suggest that there is a specific accumulation of fibronectin in the thickened basal lamina. Fibronectin functions principally as an adhesion molecule in basal lamina, providing anchorage for endothelial cells. Recent experimental evidence has reported that the synthesis of fibronectin by endothelial cells may be specifically increased by a rise in intracellular cyclic adenosine monophosphate. ${ }^{18}$ It is possible that this may be a mechanism by which circulating products of cigarette smoke influence the function of the endothelial cell, inducing the production of specific components of the basal lamina. 
The venous wall is nurtured by the luminal blood supply; thickened endothelial basal lamina may interfere with this process by acting as a barrier to the diffusion of macromolecules across the intima. The thickened basal lamina may also interfere with the normal signalling and communication between endothelial cells and underlying mesenchymal cells. Such hindrance to cell to cell communication by cytokines or endothelium derived relaxing factor during the arterialisation of a vein graft could contribute to the development of intimal hyperplasia and graft stenosis. Hence the thickened basal lamina in veins from smokers could contribute to the increased rate of failure of vein grafts in smokers. The thickened basal lamina may also have use as a pathological marker of smoking, enabling the identification of the vein at risk of graft occlusion. Further work is required to determine more precisely the time scale over which these changes are reversible.

Our results suggest that the endothelial basal lamina is thickened in heavy smokers and that this thickening contains fibronectin. Smoking may therefore influence the function of the endothelial cell and the structure of the venous intima and contribute to an increased risk of graft occlusion.

We thank Mr Ian Shore for his help with the preparation of specimens for electron microscopy.

1 Kent KC, Whittemore AD, Mannick JA. Short-term and midterm results of an all-autologous tissue policy for infrainguinal reconstruction. $f$ Vasc Surg. 1989;9: 107-14.
2 Bourassa MG, Enjalbert M, Campeau L, Lesperance J. Progression of atherosclerosis in coronary artery and bypass grafts ten years later. Am $\mathcal{F}$ Cardiol 1984 53:102C-7C

3 Fitzgibbon GM, Leach AJ, Kafka HP. Atherosclerosis of coronary artery bypass grafts and smoking. Can Med Assoc 7 1987;136:45-7.

4 Rutherford RB, Jones DN, Bergqvist D. Factors affecting the patency of infrainguinal bypass. $f$ Vasc Surg 1988 ; 8:236-46.

5 Wiseman S, Kenchington G, Dain R, et al. Influence of smoking and plasma factors on patency

6 Donaldson MC, Mannick JA, Whittemore AD. Causes of primary graft failure after in situ saphenous vein bypass grafting. $\mathcal{F}$ Vasc Surg 1992;15:113-20.

7 Asmussen I, Kjeldsen K. Intimal ultrastructure of human umbilical arteries: observations on arteries from newborn children of smoking and non-smoking mothers. $C i$ Res 1975;36:579-89.

8 Bylock A, Bondjers G, Jansson I, et al. Surface ultrastructure of human arteries with special reference to the effects of smoking. Acta Path Microbiol Scan 1979;87: 201-9.

9 Woodrow DF, Shore I, Moss J, et al. Immunoelectron microscopic studies of immune complex deposits and basement membrane components in IgA nephropathy. basement membrane compo $1989 ; 157: 47-57$.

10 Mohan PS, Spiro RG. Macromolecular organisation of basement membranes. Characterisation and comparison
of glomerular basement membrane and lens capsule components by immunochemical and lectin affinity procedures. $\mathcal{F}$ Biol Chem 1986;261:4328-36.

11 Fonkalsrud EW, Sanchez M, Zerubavel R, et al. Arterial endothelial changes after ischaemia and perfusion. Surg Gynecol Obstet 1976;142:715-21.

12 Bloom A. The nature of diabetes. $f R$ Soc Med 1978;71: 170-83.

13 Ashton N. Vascular basement membrane changes in diabetic retinopathy. $\mathrm{Br}$ f Ophthalmol 1974;58:344-51.

14 Kilo C, Vogler N, Williamson JR. Muscle capillary basement membrane changes related to ageing and to diabetes mellitus. Diabetes 1972;21:881-99.

15 Pierce GB, Nakane PK. Basement membranes: synthesis and deposition in response to cellular injury. Lab Invest and deposition in

16 Martinez-Hernandez A, Amenta PS. The basement membrane in pathology. Lab Invest 1983;48:656-77.

17 Fujiwara S, Wiedemann H, Timpl R, et al. Structure and interactions of heparan sulphate proteoglycans from interactions of heparan sulphate proteoglycans from a mouse tumour base

18 Cagliero E, Roth $\mathrm{T}$, Roy $\mathrm{S}$, et al. Expression of genes related to the extracellular matrix in human endothelia cells. $\mathcal{F}$ Biol Chem 1991;266:14244-50. 